\title{
El arbitraje médico y la pandemia de COVID-19 en México
}

The medical arbitration and COVID-19 pandemic in Mexico

Daniela Carrasco Zúñiga,* Miguel Ángel Lezana Fernández,*

Fernando Meneses González*

El 26 de diciembre de 2019 un hombre de 41 años fue ingresado en el Hospital Central de Wuhan, China con un cuadro respiratorio parecido a una neumonía y unas semanas después se identificó, en muestra de líquido broncoalveolar, un virus y su secuencia genómica al que nombraron inicialmente WH-Human 1 coronavirus (WHCV).? Posteriormente este virus fue renombrado por el grupo de estudio de Coronaviridae del Comité Internacional de Taxonomía de virus como virus SARSCoV-2. ${ }^{2}$ La Organización Mundial de la Salud (OMS) declara esta infección en salud pública de interés internacional ${ }^{3}$ y el 11 de febrero de 2020, la OMS nombra la enfermedad como COVID-19.4 Esta pandemia afectó a México desde el mes de febrero de 2020, la gravedad de la misma obligó a los países a instalar una serie de medidas de protección poblacional para reducir el riesgo de contagio y, en consecuencia, de la enfermedad y muerte.

En México se implantaron una serie de medidas, desde poblacionales, como lo fue el confinamiento, hasta individuales como el lavado de manos, la sana distancia y el uso de cubrebocas. La pandemia modificó el desarrollo de las actividades de la población y de las instituciones, tanto públicas como privadas.

La Comisión Nacional de Arbitraje Médico, así como las Comisiones Estatales de Arbitraje Médico, como instituciones públicas que ofrecen mecanismos alternativos de solución de controversias entre usuarios y prestadores de servicios médicos, tenían el reto de continuar operando sus servicios al público o a los profesionales de salud. Un reto que fue y sigue siendo mayúsculo ya que, ante situaciones extraordinarias o diferentes a las rutinarias en la atención de la salud, las instituciones se resienten y hay un impacto en la calidad de la atención; ${ }^{5}$ esto puede generar una mayor probabilidad de incidentes en la atención y, en consecuencia, un incremento en las solicitudes de orientación o quejas por parte de los usuarios de los servicios de salud.

En este número de la Revista CONAMED se publican las acciones que realizaron tanto la CONAMED como las comisiones estatales de arbitraje médico de los estados de Hidalgo, Puebla, Nuevo León, Tabasco y Yucatán, para adaptarse a las nuevas condiciones de trabajo obligadas por la pandemia, la problemática que atendieron y los resultados obtenidos de su operación.

Sirva este número también como un reconocimiento y agradecimiento a las instituciones de salud de nuestro país, al personal de salud y a todas aquellas organizaciones que participaron con su máximo esfuerzo en la atención de la pandemia.
* Dirección General de Difusión e Investigación. Comisión Nacional de Arbitraje Médico. México.

Correspondencia: DCZ, dcarrasco@conamed. gob.mx

Conflicto de intereses:

Los autores declaran no tener conflicto de intereses.

Citar como: Carrasco ZD, Lezana FMÁ, Meneses GF. El arbitraje médico y la pandemia de COVID-19 en México. Rev CONAMED. 2021; 26/supl. 1): s3-s4. https://dx.doi. org/10.35366/102575

Financiamiento: No hubo financiamiento. 


\section{REFERENCIAS}

1. Wu F, Zhao S, Yu B et al. A new coronavirus associated with human respiratory disease in China. Nature. 2020; 579: 265-269. Available in: https://doi.org/10.1038/s41586020-2008-3

2. Coronaviridae Study Group of the International Committee on Taxonomy of Viruses. The species aevere acute respiratory syndrome-related coronavirus: classifying 2019nCoV and naming it SARS-CoV-2. Nat Microbiol. 2020; 5 : 536-544. Available in: https://doi.org/10.1038/s41564-0200695-z
3. PAHO/WHO Response. 31 march 2020. Report 1. COVID-19 Available in: https://iris.paho.org/bitstream/ handle/10665.2/52403/COVID-19SitRepl_eng. pdf? sequence=7\&isAllowed=y

4. WHO. WHO Director-General's remarks at the media briefing on 2019-nCoV on 11 February 2020. Available in: https://www.who.int/dg/speeches/detail/who-directorgeneral-s-remarksat-the-media-briefing-on-2019-ncovon-11-february-2020

5. Braithwaite J. Quality of care in the COVID-19 era: a global perspective, IJQHC Communications. 2021; 1 (1): Iyab003. Available in: https://doi.org/10.1093/ijcoms/lyab003 